\title{
Identification of CD24 as a potential diagnostic and therapeutic target for malignant pleural mesothelioma
}

\author{
Sivasundaram Karnan ${ }^{1}$, Akinobu Ota (1] ', Hideki Murakami², Md Lutfur Rahman', Muhammad Nazmul Hasan', \\ Md Wahiduzzaman', Ichiro Hanamura ${ }^{3}$, Lam Quang Vu³, Akihito Inoko², Toshinori Hyodo ${ }^{1}$, Hiroyuki Konishi@', \\ Shinobu Tsuzuki ${ }^{1}$ and Yoshitaka Hosokawa ${ }^{1}$
}

\begin{abstract}
Malignant pleural mesothelioma (MPM) is an aggressive malignancy of the pleura that is currently incurable due to the lack of an effective early diagnostic method and specific medication. The CDKN2A (p16) and NF2 genes are both frequently mutated in MPM. To understand how these mutations contribute to MPM tumor growth, we generated NF2/p16 double-knockout (DKO) cell clones using human MeT-5A and HOMC-B1 mesothelial cell lines. Cell growth and migration activities were significantly increased in DKO compared with parental cells. CDNA microarray analysis revealed differences in global gene expression profiles between DKO and parental cells. Quantitative PCR and western blot analyses showed upregulation of CD24 concomitant with increased phosphorylation of AKT, P70S6K, and c-Jun in DKO clones. This upregulation was abrogated by exogenous expression of NF2 and p16. CD24 knockdown in DKO cells significantly decreased TGF- $\beta 1$ expression and increased expression of E-cadherin, an epithelial-mesenchymal transition marker. CD24 was highly expressed in human mesothelioma tissues (28/45 cases, 62\%) and associated with the loss of NF2 and p16. Public data analysis revealed a significantly shorter survival time in MPM patients with high CD24 gene expression levels. These results strongly indicate the potential use of CD24 as a prognostic marker as well as a novel diagnostic and therapeutic target for MPM.
\end{abstract}

\section{Introduction}

Malignant pleural mesothelioma (MPM) is an aggressive malignancy of the pleura that is associated with asbestos exposure after 30-40 years of latency ${ }^{1,2}$. Patients with MPM are usually diagnosed at an advanced stage of the disease and their prognosis remains poor. The median survival after diagnosis is 6-12 months and the standard treatment agents,

\footnotetext{
Correspondence: Sivasundaram Karnan (skarnan@aichi-med-u.ac.jp) or Yoshitaka Hosokawa (hosokawa@aichi-med-u.ac.jp)

${ }^{1}$ Department of Biochemistry, Aichi Medical University School of Medicine,

Nagakute, Aichi, Japan

2Department of Pathology, Aichi Medical University School of Medicine,

Nagakute, Aichi, Japan

Full list of author information is available at the end of the article

These authors contributed equally: Sivasundaram Karnan, Akinobu Ota, Hideki Murakami

Edited by: Maria Victoria Niklison Chirou
}

pemetrexed and cisplatin, are relatively ineffective at increasing survival time ${ }^{2,3}$. Despite the restricted and banned use of asbestos, MPM is increasingly being diagnosed in young individuals and women ${ }^{4,5}$. Other risk factors, including exposure to erionite fibers, therapeutic ionizing radiation to the chest, and germline BRCA1-associated protein 1 (BAP1)inactivating mutations, have been causally linked to $\mathrm{MPM}^{1}$. Therefore, new therapies based on improving patient survival are still required ${ }^{6,7}$.

Molecular biological studies in MPM have revealed frequent genetic alterations of tumor suppressor genes, including neurofibromatosis 2 (NF2), cyclin-dependent kinase inhibitor $2 A$ (p16), and $B A P 1^{8-15}$. Furthermore, multiplex molecular analyses with whole-exome sequencing, highdensity array comparative genomic hybridization, and immunohistochemistry (IHC) have disclosed that somatic

\section{(c) The Author(s) 2020}

(c) (i) Open Access This article is licensed under a Creative Commons Attribution 4.0 International License, which permits use, sharing, adaptation, distribution and reproduction cc) in any medium or format, as long as you give appropriate credit to the original author(s) and the source, provide a link to the Creative Commons license, and indicate if changes were made. The images or other third party material in this article are included in the article's Creative Commons license, unless indicated otherwise in a credit line to the material. If material is not included in the article's Creative Commons license and your intended use is not permitted by statutory regulation or exceeds the permitted use, you will need to obtain permission directly from the copyright holder. To view a copy of this license, visit http://creativecommons.org/licenses/by/4.0/. 
BAP1 mutations and deletions were present in $>60 \%$ of MPM patients ${ }^{16,17}$. We recently reported that fibroblast growth factor receptor 2 is highly expressed in NF2knockout mesothelial cell lines and is a candidate molecule for the development of therapeutic and diagnostic strategies targeting $\mathrm{MPM}^{18}$. A previous study using NF2 and p16 double-knockout (DKO) mice indicated that these genes, when mutated, contribute to mesothelioma development ${ }^{19}$. However, it remains unclear how these complex mutations contribute to tumor formation in MPM. We established NF2/p16-DKO cell clones in human immortalized mesothelial cell lines and identified several genes regulated by NF2 and $\mathrm{p} 16$.

CD24 is a glycosylphosphatidylinositol-linked sialoprotein that was shown to be present in the cell membranes of $B$ lymphocyte precursors, neutrophils, neuronal cells, and some epithelial cells, and is highly expressed in several types of cancers $^{20-30}$. It was also shown to be an independent prognostic marker of reduced patient survival in ovarian cancer and non-small cell lung cancer ${ }^{21,22}$. Furthermore, CD24 is reportedly related to epithelial-mesenchymal transition (EMT) in ovarian and pancreatic cancers ${ }^{31,32}$. The present study found that CD24 is highly expressed in NF2/16-DKO cell clones and human MPM tissues, highlighting it as a potential diagnostic and therapeutic target for MPM.

\section{Results}

\section{NF2/p16 DKO enhances cell proliferation, colony} formation, and migration in MeT-5A and HOMC-B1 human mesothelial cell lines

To investigate the roles of NF2 and p16 in mesothelial cells, we established two NF2-knockout clones (NF2$\mathrm{KO \# 1}$ and \#2), two p16-knockout clones (p16-KO\#1 and $\# 2$ ), and two NF2/p16-DKO cell clones (DKO \#1 and \#2) using MeT-5A and HOMC-B1 human mesothelial cell lines with the CRISPR/Cas9 system (Fig. 1a). Protein expression of NF2 and p16 was not detected in DKO \#1 and \#2 (Fig. 1b). Also, no p14ARF expression, an alternative form of $\mathrm{p} 16$, was detected after targeting exon 1 of p16 (Fig. 1b). We examined cell proliferation of the established clones using MTT (3-(4,5-dimethylthiazol-2yl)-2,5-diphenyltetrazolium bromide) assay and found that the cell growth ratio was significantly increased in the DKO clones compared with that in the parental cells (Fig. 2a). The DKO clones also formed more colonies in soft agar compared with the parental cells (Fig. 2b). Furthermore, migration activity was significantly higher in the DKO clones (Fig. 2c). These results indicate that NF2/ p16 inactivation enhances cell growth, clonogenicity, and migration in the mesothelial cells.

\section{Gene expression change induced by disruption of NF2/p16}

To identify genes involved in enhanced cell growth and migration, we performed comprehensive cDNA microarray analysis in the DKO, NF2-KO, and p16-KO clones, as well as the parental cells. To compare gene expression profiles, normalized values of raw microarray data were calculated and clustered according to differential gene expression. Expression of 29 genes was upregulated $>20.0$-fold (Supplementary Table S3) and 76 genes were downregulated $<0.05$-fold (Supplementary Table S4). Clustering of the 105 genes showed a distinct gene expression pattern among the DKO, NF2-KO, and p16/p14-KO clones, and the parental cells (Fig. 3a). To further confirm the effect of NF2/p16 on changes to gene expression, we generated clones exogenously expressing NF2 in the NF2-KO clone (exogenous $\mathrm{NF} 2 / \mathrm{NF} 2-\mathrm{KO}$ ), exogenous p16 in the p16-KO clone (exogenous p16/p16-KO), exogenous NF2 and p16 in the DKO clone (exogenous NF2 and p16/DKO). We then performed quantitative real-time PCR (qRT-PCR) analysis for four cell surface receptor genes (PTN, CD24, BMP7, and $C A D M 1)$, because their protein products are easily detectable by molecular diagnosis and are also related to cell survival, proliferation, or tumor growth. The qRT-PCR results revealed increased expression of PTN, CD24, $B M P 7$, and $C A D M 1$ genes in the DKO clones compared with the parental cells and NF2-KO and p16-KO clones (Fig. 3b). Furthermore, increased expression of PTN, CD24, and $B M P 7$ was abrogated in the DKO clones exogenously expressing NF2 and p16 (exogenous NF2 and p16/DKO) (Fig. $3 \mathrm{~b}$ ), strongly suggesting that the affected gene products were downstream of NF2 and p16 signaling.

\section{Effect of NF2/p16 DKO on CD24 expression and cell cycle- related molecules}

CD24 has been implicated in the pathogenesis of a wide range of human cancers and emerged as a novel anticancer application in a panel of solid cancers ${ }^{33-36}$. Therefore, we focused on CD24 as its expression was increased in DKO cells (Fig. 4a). Exogenous expression of NF2 and p16 resulted in reduced CD24 expression in NF2 and p16/ DKO clones (Fig. 4a), indicating that CD24 expression is negatively regulated by NF2/p16 signaling in mesothelial cells.

Next, the phosphorylation levels of AKT, p70S6K, and c-Jun were investigated and quantified to determine cell growth signaling. As shown in Fig. 4a, b, we observed increased phosphorylation of cellular growth and proliferation-related signaling molecules, including AKT, p70S6K, and c-Jun, in the DKO clones. PTN, BMP7, and CADM1 protein products, as well as CD24, were increased in the DKO clones (Fig. 4a). To confirm the effect of NF2 and p16 on the expression of these signaling proteins, we utilized DKO clones exogenously expressing NF2 and p16 (exogenous NF2 and p16/DKO) (Fig. 4a). In the exogenous NF2 and p16/DKO clones, increased expression of CD24, PTN, BMP7, CADM1, p-pAKT, $\mathrm{p}$-p70S6K, and p-c-Jun was downregulated, strongly 


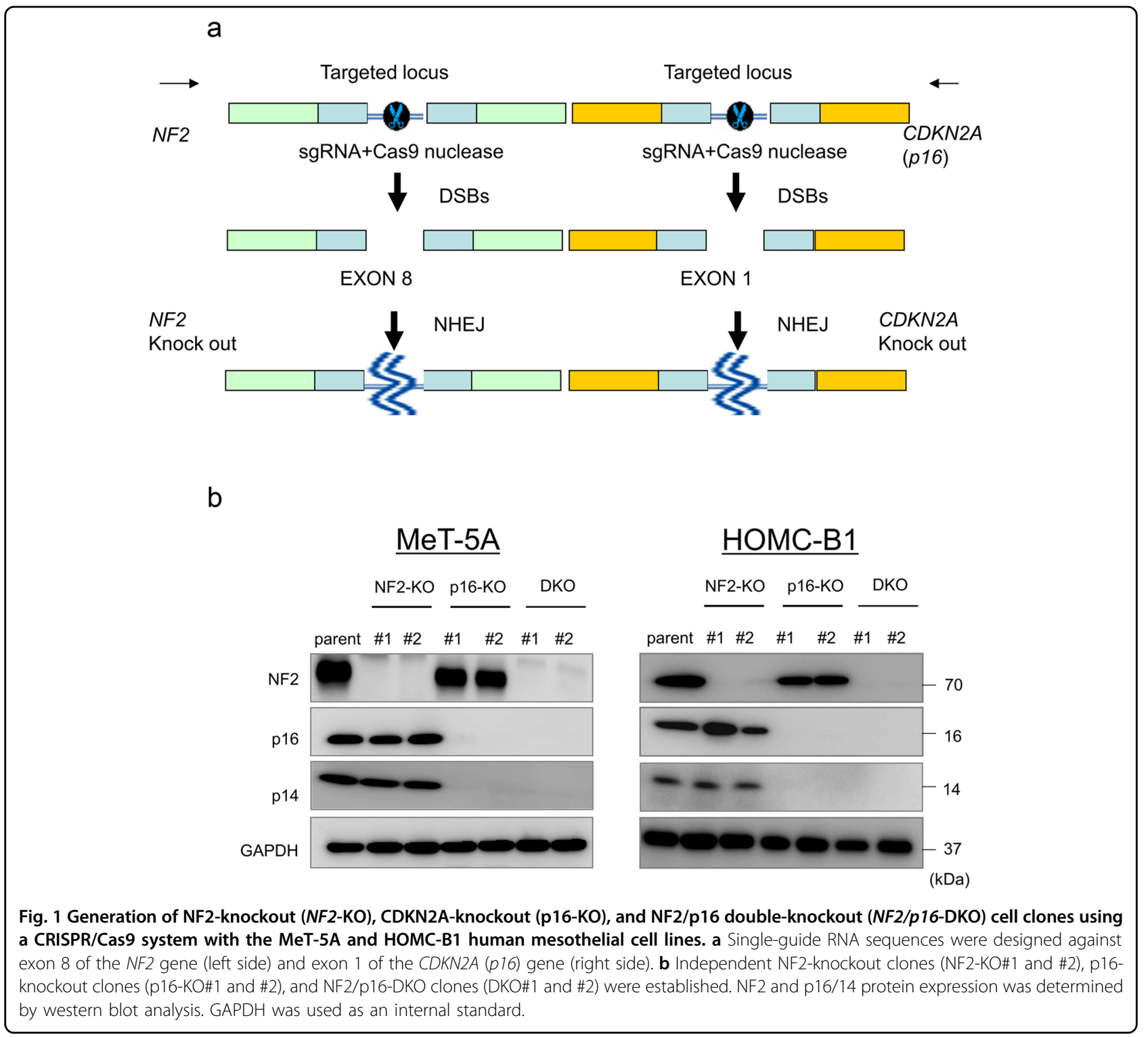

suggesting that these proteins function downstream of NF2 and p16 signaling. Different expression patterns between CADM1 mRNA and its protein were observed in HOMC-B1 cells. Different expression patterns of PTN and BMP7 proteins from their mRNAs in MeT-5A and HOMC-B1 cells were also observed. The difference would be, in part, due to a post-transcriptional modification.

\section{CD24 knockdown downregulates TGF- $\beta 1$ and cell proliferation in the absence of NF2/p16 gene expression}

To investigate the involvement of CD24 in cell proliferation, we knocked down CD24 in the DKO clones and parental cells. MTT assay showed that cell growth was significantly decreased in the CD24 shRNA-DKO cells compared with the DKO clones (Fig. 5a). Furthermore, colony formation also decreased in the CD24 shRNA-
DKO cells (Supplementary Fig. S1). These results strongly suggest that CD24 may play an important role in cell growth and clonogenicity of mesothelioma cells with loss of p16 and NF2 expression.

In DKO cell clones, we observed gene expression changes characteristic of EMT phenotypes, such as increased expression of transforming growth factor- $\beta 1$ (TGF- $\beta 1$ ) (as an inducer of EMT phenotypes), and Snail and $\mathrm{N}$-cadherin (as mesenchymal markers). Notably, $C D 24$ knockdown decreased expression of TGF- $\beta 1$, Snail, and $\mathrm{N}$-cadherin, and increased expression of E-cadherin in DKO clones (Fig. 5b), strongly suggesting that CD24 may be related to the EMT phenotype. The TGF- $\beta 1$ inhibitor, vactosertib, did not affect expression of CD24 in DKO clones, implying that CD24 functions upstream of TGF- $\beta 1$ expression (Fig. $5 \mathrm{c}$ ). Increased phosphorylation of 
a

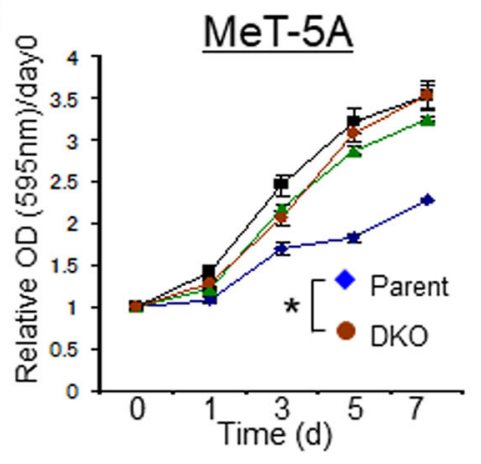

b
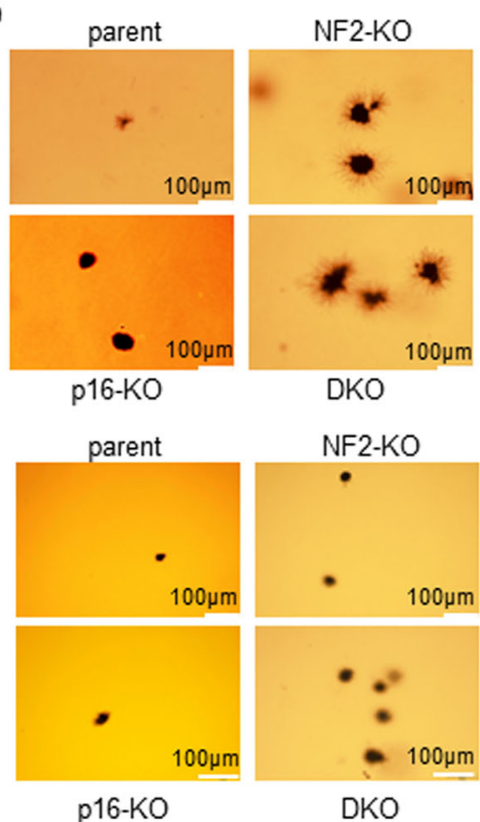

C

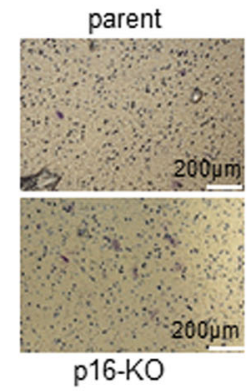

NF2-KO
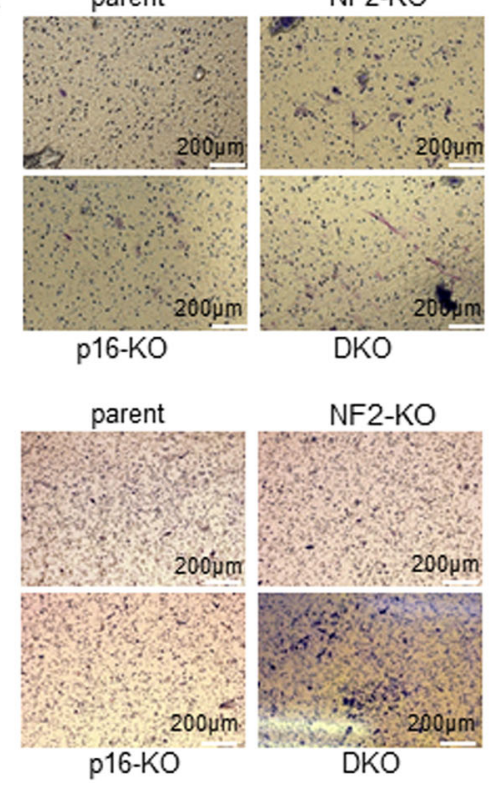

$\underline{\text { HOMC-B1 }}$

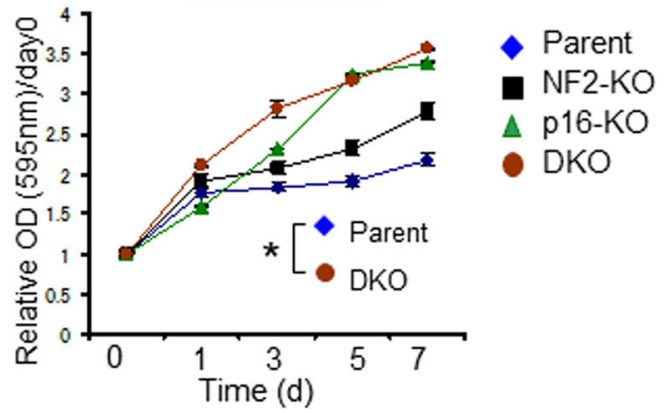

$\underline{\mathrm{MeT}-5 \mathrm{~A}}$

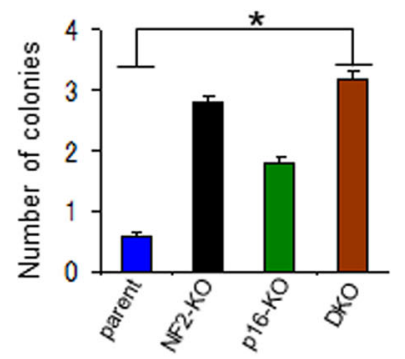

HOMC-B1

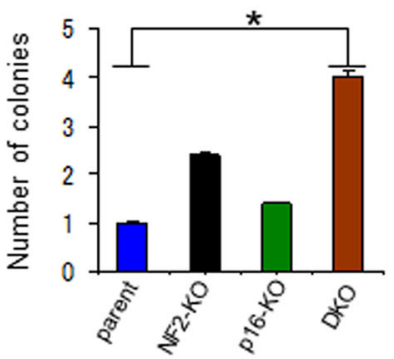

MeT-5A

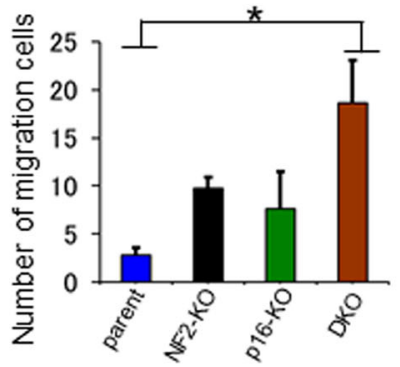

HOMC-B1

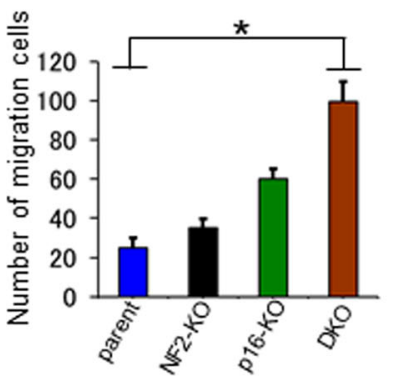

Fig. 2 (See legend on next page.) 
(see figure on previous page)

Fig. 2 Cellular phenotype of parent, NF2-KO, p16-KO, and NF2/p16-DKO-Met-5A and HOMC-B1 cells. a MTT analysis of the growth rate in parental cells, NF2-KO cell clones, p16-KO cell clones, and NF2/p16-DKO cell clones. Data are mean \pm SEM $(n=3)$. ${ }^{*} P<0.05$, statistically significant difference between parental and DKO cells. b Representative soft agar colony formation assays are shown. Right bar graphs represent the number of stained colonies. Scale bar $=100 \mu \mathrm{m}$. Data represent mean \pm SEM $(n=3)$. ${ }^{*} P<0.05$, statistically significant difference. c Representative migration assays using a Boyden chamber are shown. The right bar graph represents the number of stained colonies. Scale bar $=200 \mu \mathrm{m}$. Data represent mean \pm SEM $(n=3)$. Asterisks $(*)$ indicate statistically significant differences $\left({ }^{*} P<0.05\right)$.

SMAD2 in DKO cells compared to parental cells and subsequent decrease after treatment with the inhibitor were also observed (Fig. 5c). Furthermore, DKO clones with higher CD24 expression showed a spindle cell morphology, which is a morphological feature of EMT (Fig. 5d). Knockdown of CD24 also led to a change in cell morphology from spindle cell to circle shape, as well as an increased number of cell-cell contacts. To obtain further experimental evidence for the EMT phenotype, immunofluorescence analyses were performed to examine the expression of desmoplakin, one of the desmosomes ${ }^{37}$. A loss of desmoplakin expression in DKO cells and a mesothelioma cell line compared to mesothelial cells was found (Supplementary Fig. S2). Taken together, these results prompted us to speculate that $\mathrm{CD} 24$ induces the EMT phenotype in mesothelial cells with loss of NF2 and $\mathrm{p} 16$.

\section{IHC analysis of CD24 expression in patients with MPM}

To investigate the role of CD24 in human MPMs, we performed immunohistochemical analysis to examine protein expression levels of CD24 in 45 MPMs and three normal mesothelium tissue samples (Table 1 and Fig. 6a). Microscopic analysis detected 8 strong (3+), 20 moderate $(2+)$, and 6 weak $(1+)$ CD24-positive signals among 45 MPM tissue samples (Fig. 6b), whereas CD24 expression was not detectable in three normal mesothelium tissues (Table 1 and Fig. 6a, left panels). Also, the CD24 expression pattern in three subtypes (epithelioid, sarcomatous, and biphasic) ${ }^{1}$ is summarized in Table S5. A high frequency of CD24 expression was observed in the epithelioid type. To further validate $C D 24$ expression in MPM patients, we analyzed a public cohort of 86 patients from The Cancer Genome Atlas Mesothelioma. Our analysis revealed that overall survival in MPM patients with higher $C D 24$ expression levels was shorter than that in those with low CD24 expression levels (Fig. 6c). According to the $\log _{2}$ value of CD24 probe, patients were divided into two groups: high $\left(\log _{2}\right.$ value $\left.>6.938, n=42\right)$ and low ( $\log _{2}$ value $\left.<6.938, n=44\right)$ CD24 expression. Thus, high $C D 24$ expression was significantly associated with overall survival $(P<0.0001)$.

Furthermore, NF2 and p16 expression, together with CD24 expression in human MPM tissue arrays, was immunohistochemically examined. CD24-positive expression showed 20 (100\%) of 20 cases with both NF2- and p16negative expression, whereas CD24-positive expression showed 8 (42\%) of 19 cases with both NF2- and p16-positive expression (Supplementary Table S6 and Supplementary Fig. S3). These results suggest that CD24-positive expression might be associated with the loss of NF2 and p16 expression in MPM tissues.

\section{Discussion}

$N F 2, p 16$, and BAP1 are the three major tumor suppressor genes that frequently undergo genomic alterations in MPMs. In the present study, we generated both NF2 and p16-knockout isogenic clones using the human normal mesothelial cell lines, MeT-5A and HOMC-B1, and showed that loss of NF2 and $p 16$ expression enhanced cell growth, clonogenicity, and migration activities with global changes in gene expression. Our findings strongly suggest that CD24 expression occurs downstream of NF2 and p16 in mesothelial cells and is correlated with overall survival of MPM patients.

CD24 is frequently overexpressed in several types of solid tumors and is correlated with poor prognosis $^{22,25,28,38,39}$. Thus, CD24 could be a potential target for a monoclonal antibody-mediated therapy. Antibodymediated therapy toward cell surface antigens, such as CD20, has been used as treatment for non-Hodgkin's lymphoma ${ }^{40,41}$. Therefore, the present study focused on CD24, as its expression is increased in DKO clones. Knockdown of $C D 24$ reduced cell growth and clonogenicity. CD24 was also reported to be related to EMT, which is an important step leading to invasion, migration, and resistance to apoptosis of various cancer cells ${ }^{28,31,32}$. EMT phenotypes are characterized by decreased expression of E-cadherin as an epithelial marker, and increased expression of TGF- $\beta 1$ as an inducer of EMT and Snail, Twist, Slug, vimentin, and N-cadherin as mesenchymal markers, and are responsible for poor prognosis in patients with various cancers ${ }^{42}$. In the present study, knockdown of $C D 24$ decreased the expression of TGF- $\beta 1$, Snail, and N-cadherin, and increased the expression of E-cadherin in DKO clones, strongly suggesting that CD24 may contribute to the EMT phenotype in the mesothelial cells. To further explore the relationship between CD24 and TGF- $\beta 1$, we examined the effect of TGF- $\beta 1$ inhibitor in the DKO cells. Knockdown of CD24 decreased the 
a
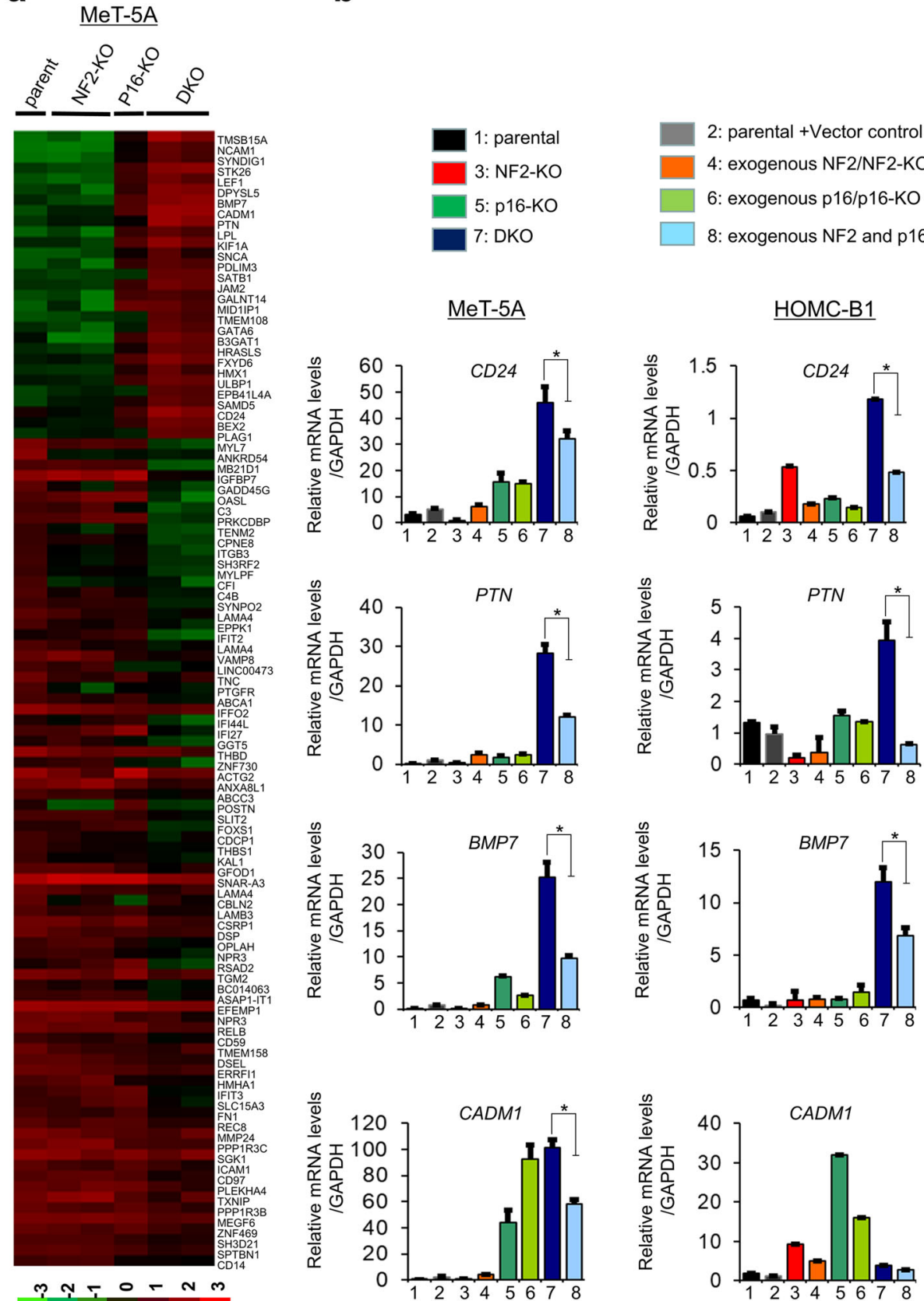

$\log _{2}$ ratio

Fig. 3 Gene expression analysis. Parental MeT-5A cells and knockout cell clones were seeded in 6-well plates and incubated for $24 \mathrm{~h}$. Total RNA was extracted and cDNA microarray analysis was performed using Agilent Whole Human Genome cDNA Microarray Kit (4×44 K; Design ID, 026652). a Heat map showing upregulated genes (29 genes; fold change $>20.0$ ) and downregulated genes (76 genes, fold change $<0.05)$ in the DKO cell clones compared with the parent cells, NF2-KO cell clones, and p16-KO cell clones. The heat map was constructed using normalized values of each sample with Tree View (Cluster 3.0) software. Corresponding upregulated or downregulated genes in the heat map are shown on the right side. b Quantitative real-time PCR (qRT-PCR) analysis. Four genes that were upregulated in DKO cell, as detected using cDNA microarray analysis, were selected for qRT-PCR analysis using the SYBR green method. Relative gene expression levels are shown after normalization to GAPDH mRNA expression. Mean values were compared with the normal control value to calculate the relative amounts of transcripts. Data represent mean \pm SEM $(n=3)$. Asterisks $(*)$ indicate statistically significant differences $\left({ }^{*} P<0.05\right)$. 


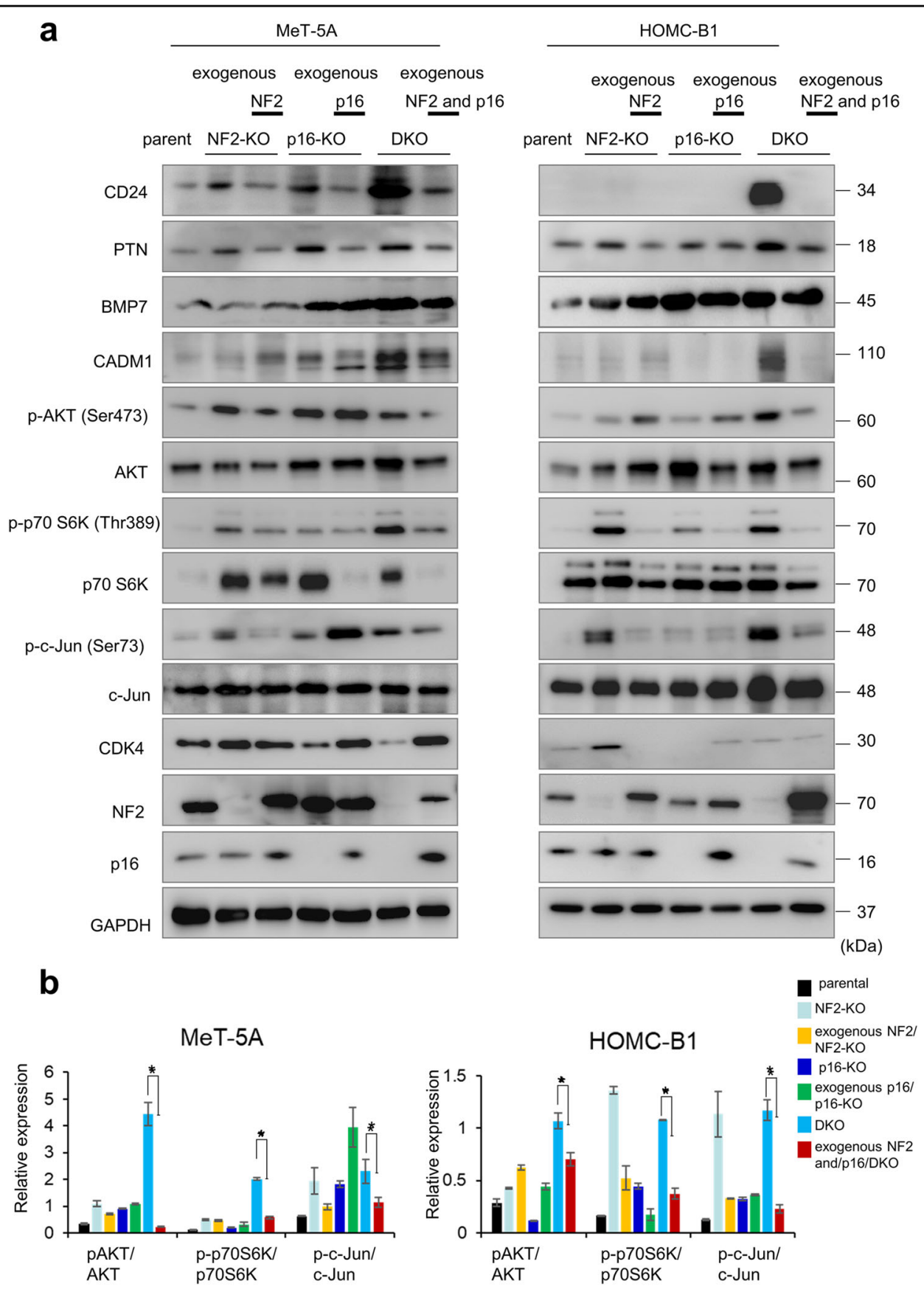

Fig. 4 Protein expression analyses. a Western blot analysis showing expression of the indicated proteins in parent cells, NF2-KO cell clones, exogenous NF2 expression/NF2-KO cell clones, p16-KO cell clones, exogenous p16 expression/p16-KO cell clones, DKO cell clones, and exogenous NF2 and p16 expression/DKO cell clones. Cell lysates obtained were used for western blotting analysis to detect protein levels using the specific antibodies listed in Supplementary Table S1. The cell lysates obtained were used for western blotting analysis. GAPDH was used as an internal control. b Quantitation of p-AKT, p70S6K, and c-Jun in MeT-5A and HOMC-B1 cells. p-AKT, p70S6K, and c-Jun expression levels were quantified by measuring the ratio between phosphorylated and total levels. Data are mean \pm SEM $(n=3)$. ${ }^{*} P<0.05$, statistically significant difference.

expression of TGF- $\beta 1$; however, TGF- $\beta 1$ inhibitor did not alter the expression of CD24, indicating that CD24 functions upstream of TGF- $\beta 1$. In addition, DKO clones with higher expression of CD24 showed a spindle cell morphology, which is a morphological feature of EMT.
We also observed that knockdown of $C D 24$ changed the morphology of spindle cells to circles. Thus, our results suggest that CD24 contributes to EMT phenotypes in mesothelial cells. Our results indicate that CD24 expression is closely associated with changes in both gene 
a
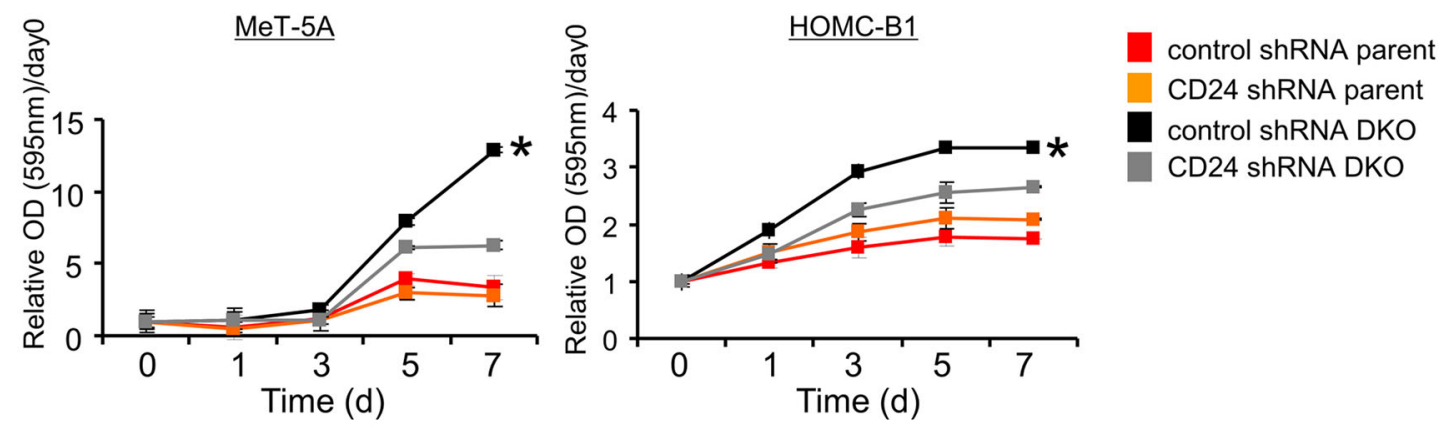

b

MeT-5A HOMC-B1

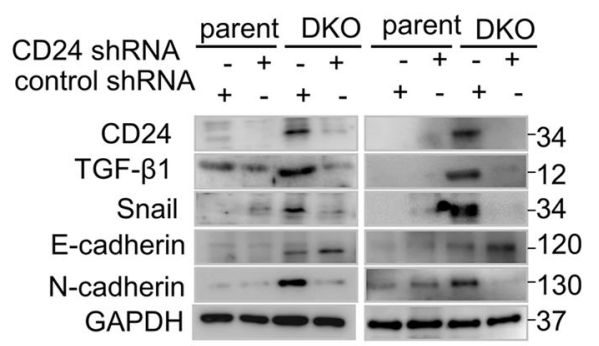

(kDa)

C

MeT-5A HOMC-B1
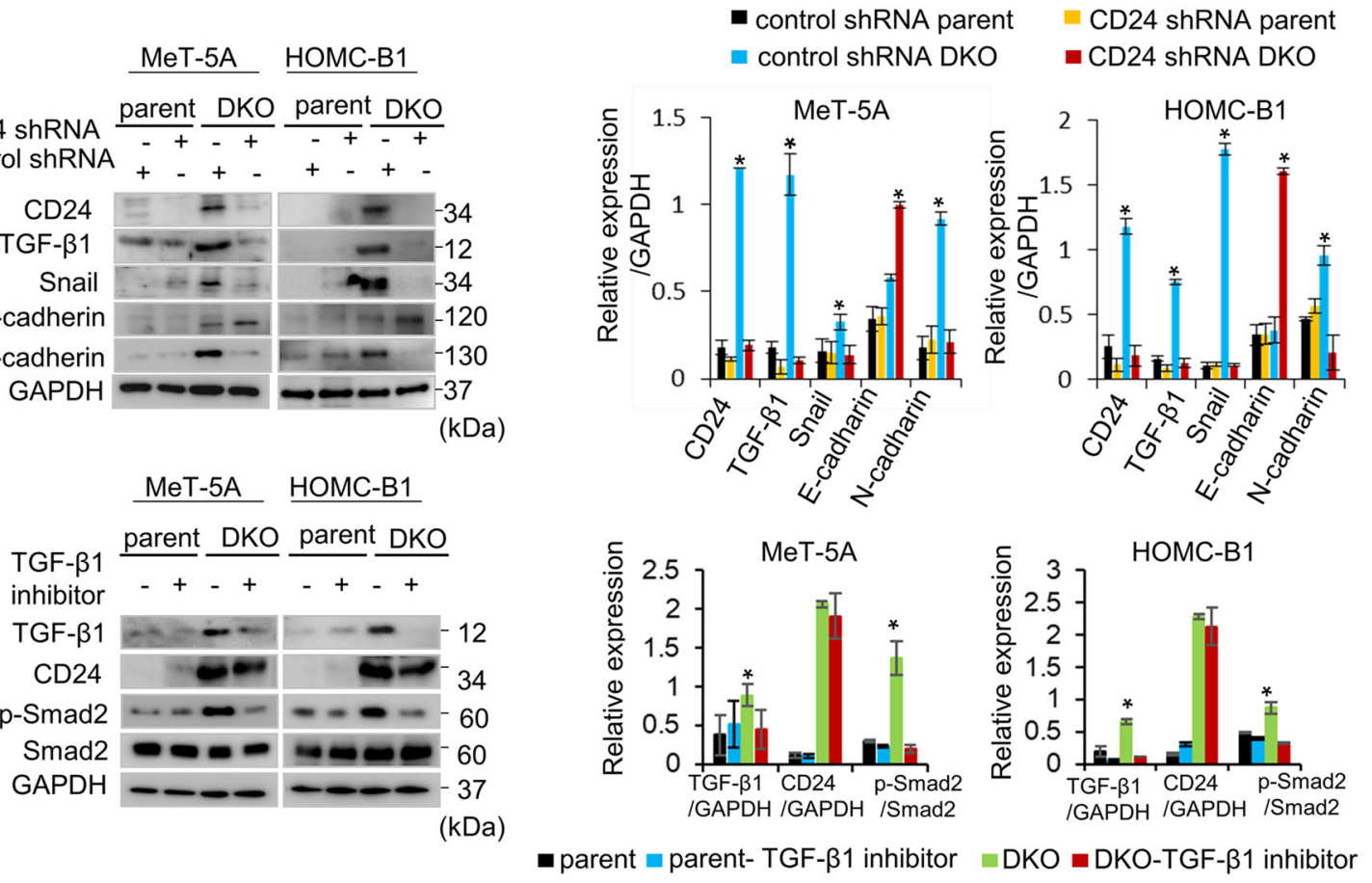

- control shRNA parent $\quad$ CD24 shRNA parent - control shRNA DKO $\quad$ CD24 shRNA DKO

d
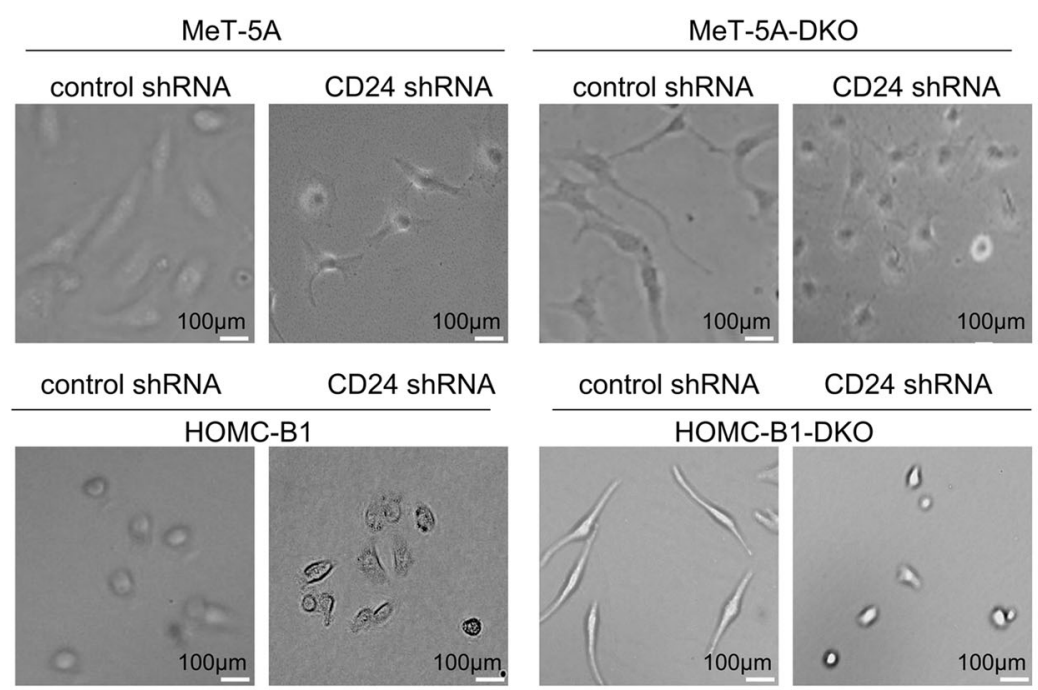

Fig. 5 (See legend on next page.) 
(see figure on previous page)

Fig. 5 CD24 knockdown reduces cell proliferation and induces gene expression and morphological changes of EMT phenotype in DKO cells. a Effect of CD24 shRNA on cell proliferation. DKO cells (Met-5A and HOMC-B1) and parent cells were transfected with CD24 shRNA and control shRNA vectors. $\mathbf{b}$ Effect of CD24 shRNA on protein expression. $\mathbf{c}$ Effect of TGF- $\beta 1$ inhibitor (vactosertib) on CD24 expression. Cells were treated with $2.5 \mu \mathrm{M}$ vactosertib for $24 \mathrm{~h}$ and cell lysates were used for western blot analysis. GAPDH or total protein was used as an internal control. $\mathbf{d}$ Effect of CD24 shRNA on morphological changes in DKO cells and parent cells. DKO cells and parent cells were transfected with CD24 shRNA and control shRNA vectors. After $48 \mathrm{~h}$ of incubation, photomicrographs were taken depicting cell morphological in control shRNA-parent, CD24 shRNA-parent cells, control shRNA-DKO cells, and CD24 shRNA-DKO cells. Scale bar $=100 \mu \mathrm{m}$. All data are mean $\pm \operatorname{SEM}(n=3) . * P<0.05$, statistically significant difference.

expression and cell morphology characteristic of EMT phenotypes. Desmosome is a cell structure specialized for cell-to-cell adhesion ${ }^{37}$. The loss of expression of many desmosome proteins has been reported in different cancers and may contribute to EMT ${ }^{43,44}$. Thus, the expression of desmoplakin, one of the desmosomes, was analyzed, and loss of desmoplakin expression was found in DKO cells and mesothelioma cell lines, providing further experimental evidence for the EMT phenotype ${ }^{45}$; therefore, we propose that CD24 expression induces the EMT phenotypes involved in the pathogenesis of MPM.

$\mathrm{IHC}$ analysis showed that CD24 was commonly expressed in $62 \%$ of human MPM tissues. Furthermore, analysis of public data revealed that MPM patients with higher expression of the CD24 gene showed a significantly shorter survival time. In addition, loss of NF2 and $p 16$ resulted in increased expression of CD24, and subsequent rescue of the two genes decreased its expression in the MeT-5A and HOMC-B1 cell lines. More importantly, CD24 expression was associated with the loss of NF2 and p16 expression in human MPM tissues. These results indicate that CD24 expression is intimately regulated by NF2 and p16 expression. Furthermore, knockdown of CD24 in the DKO clones led to retardation of cell growth and colony formation, strongly suggesting that CD24 may play a pivotal role in the proliferation and clonogenicity of DKO cells.

In the present study, global gene expression changes in response to loss of NF2 and p16 in the MeT-5A and HOMC-B1 human mesothelial cell lines were demonstrated. CRISPR/Cas9-mediated loss of NF2 and $p 16$ enhanced cell proliferation and CD24 expression, and disruption of $C D 24$ reduced the proliferation of the cells. Although the molecular mechanisms underlying the upregulation of CD24 via loss of NF2 and p16 remain unclear, CD24 was commonly expressed in MPM tissues and was associated with poor prognosis of MPM patients. Therefore, CD24 may be used as a prognostic marker as well as a novel diagnostic and therapeutic target for MPM. Further studies are warranted to develop a new therapeutic approach for the treatment of MPM.

\section{Materials and methods Cell culture}

The immortalized normal human mesothelial cell lines, MeT-5A (pleural mesothelial) and HOMC-B1 (omental mesothelial; epithelioid type), and mesothelioma cell lines (Y-MESO-9) were kindly provided by Dr. Y. Sekido at the Division of Molecular Oncology, Aichi Cancer Center Research Institute, Nagoya, Japan. The HOMC-B1 cell line was maintained as described previously ${ }^{46}$. The MeT5A was maintained in RPMI-1640 (Wako, Osaka, Japan) medium containing $10 \%$ fetal bovine serum (Sigma) and $1 \%$ penicillin/streptomycin (Wako) at $37^{\circ} \mathrm{C}$ in a $5 \% \mathrm{CO}_{2}$ humidified atmosphere.

\section{Gene knockout using the clustered regularly interspaced short palindromic repeat (CRISPR)/Cas9 system}

The CRISPR/Cas9 system was used to disrupt expression of the NF2 and CDKN2A(p16) genes as described previously ${ }^{47}$. pSpCas9(BB)-2A-GFP (PX458) was a gift from Feng Zhang (Addgene plasmid \#48138) ${ }^{47}$. In brief, a single-guide RNA (sgRNA) sequence was selected using an optimized CRISPR design (http://crispr.mit.edu/). The sgRNA sequence used for NF2 was $5^{\prime}$-AAACATCTCGT ACAGTGACA- $3^{\prime}$ and the sequence used for $p 16$ was $5^{\prime}-\mathrm{A}$ CCGTAACTATTCGGTGCGT- $3^{\prime}$, corresponding to exons 8 and 1, respectively. Plasmids expressing hCas9 and the sgRNA were prepared by ligating oligonucleotides into the BbsI site of PX458 (NF2/PX458 and p16/PX458). Knockout clones were established by electroporation of $1 \mu \mathrm{g}$ of NF2/PX458 or $p 16 / \mathrm{PX} 458$ plasmid into $1 \times 10^{6}$ cells using a 4D-Nucleofector system instrument (Lonza Japan, Tokyo, Japan). Three days post transfection, cells expressing green fluorescent protein were sorted using BD FACSARIA III (BD bioscience). A single clone was selected, expanded, and used for biological assays.

\section{Construction of RNAi vectors and expression vectors}

RNA interference vectors were constructed by inserting shRNA oligonucleotides into the pLentiLox3.7 plasmid (Addgene) under the control of the U6 promoter. One shRNA oligonucleotide was designed for the target sequence of the hairpin loop of CD24 (sh, 5'-TGCATTG ACCACGACTAA- $3^{\prime}$ ). A control shRNA vector was also constructed using a scrambled (scr) CD24 sequence (scr, 5'-GGATAAACTAAGGGATAGGAA-3'). DKO and parent cells $\left(1 \times 10^{6}\right.$ cells $)$ were nucleofected with $1 \mu \mathrm{g}$ of each vector using a $4 \mathrm{D}$-Nucleofector instrument (Lonza Japan). After $48 \mathrm{~h}$ of incubation, cell lysates were prepared and used for western blot analysis. 
Table 1 Summary of immunohistochemistry in this study.

\begin{tabular}{|c|c|c|c|c|c|c|c|}
\hline Case nos. & Age & Sex & Organ (anatomic site) & Pathology diagnosis & Stage & CD24 intensity & Proportion (\%) \\
\hline 1 & 64 & M & Thoracic cavity & Malignant mesothelioma of chest wall & । & $1+$ & 100 \\
\hline 2 & 48 & M & Thoracic cavity & Malignant mesothelioma of right pleura & । & 0 & - \\
\hline 3 & 58 & $\mathrm{~F}$ & Thoracic cavity & Malignant mesothelioma of pleura & । & $2+$ & 100 \\
\hline 4 & 49 & $\mathrm{~F}$ & Thoracic cavity & Malignant mesothelioma of pleura & । & $2+$ & 60 \\
\hline 5 & 22 & M & Thoracic cavity & Malignant mesothelioma of pleura & । & $1+$ & 60 \\
\hline 6 & 49 & M & Thoracic cavity & Malignant mesothelioma of pleura & । & $3+$ & 100 \\
\hline 7 & 32 & M & Thoracic cavity & Malignant mesothelioma of pleura & । & $2+$ & 100 \\
\hline 8 & 29 & M & Thoracic cavity & Malignant mesothelioma of pleura & । & $2+$ & 60 \\
\hline 9 & 31 & $\mathrm{~F}$ & Thoracic cavity & Malignant mesothelioma of thoracic cavity & । & $2+$ & 100 \\
\hline 10 & 70 & $\mathrm{~F}$ & Thoracic cavity & Malignant mesothelioma of right pleura & $\|$ & $2+$ & 100 \\
\hline 11 & 47 & M & Thoracic cavity & Malignant mesothelioma of left pleura & $\|$ & 0 & - \\
\hline 12 & 60 & M & Thoracic cavity & Malignant mesothelioma of pleura & $\|$ & $3+$ & 100 \\
\hline 13 & 46 & M & Thoracic cavity & Malignant mesothelioma of thoracic cavity & $\|$ & $2+$ & 100 \\
\hline 14 & 35 & M & Thoracic cavity & Malignant mesothelioma of pleura & $\|$ & 0 & - \\
\hline 15 & 83 & M & Thoracic cavity & Malignant mesothelioma of pleura & III & 0 & - \\
\hline 16 & 56 & M & Thoracic cavity & Malignant mesothelioma of pleura mediastinalis & III & 0 & - \\
\hline 17 & 67 & $\mathrm{~F}$ & Thoracic cavity & Malignant mesothelioma of right thoracic cavity & IV & $3+$ & 100 \\
\hline 18 & 57 & M & Abdominal cavity & Malignant mesothelioma of peritoneum & । & $3+$ & 100 \\
\hline 19 & 29 & M & Abdominal cavity & Malignant mesothelioma of peritoneum & । & 0 & - \\
\hline 20 & 71 & M & Abdominal cavity & Malignant mesothelioma of mesostenium & $\|$ & $2+$ & 100 \\
\hline 21 & 63 & $\mathrm{~F}$ & Abdominal cavity & Malignant mesothelioma of peritoneum & $\|$ & $2+$ & 100 \\
\hline 22 & 48 & $\mathrm{~F}$ & Abdominal cavity & Malignant mesothelioma of peritoneum & $\|$ & $2+$ & 100 \\
\hline 23 & 60 & $\mathrm{~F}$ & Abdominal cavity & Malignant mesothelioma of peritoneum & $\|$ & $2+$ & 100 \\
\hline 24 & 60 & $\mathrm{~F}$ & Abdominal cavity & Malignant mesothelioma of peritoneum & $\|$ & 0 & - \\
\hline 25 & 47 & M & Abdominal cavity & Malignant mesothelioma of peritoneum & $\|$ & $2+$ & 100 \\
\hline 26 & 33 & $\mathrm{~F}$ & Abdominal cavity & Malignant mesothelioma of peritoneum & $\|$ & $1+$ & 100 \\
\hline 27 & 76 & $\mathrm{~F}$ & Abdominal cavity & Malignant mesothelioma of hypogastrium & $\|$ & $3+$ & 100 \\
\hline 28 & 78 & M & Abdominal cavity & Malignant mesothelioma of hypogastrium & $\|$ & $1+$ & 100 \\
\hline 29 & 41 & $\mathrm{~F}$ & Abdominal cavity & Malignant mesothelioma of hypogastrium & $\|$ & 0 & - \\
\hline 30 & 28 & M & Abdominal cavity & Malignant mesothelioma of left retroperitoneum & $\|$ & $2+$ & 100 \\
\hline 31 & 5 & $\mathrm{~F}$ & Abdominal cavity & Malignant mesothelioma of right superior belly & $\|$ & $2+$ & 100 \\
\hline 32 & 45 & M & Abdominal cavity & Malignant mesothelioma of peritoneum & $\|$ & $1+$ & 100 \\
\hline 33 & 69 & M & Abdominal cavity & Malignant mesothelioma of peritoneum & $\|$ & $3+$ & 100 \\
\hline 34 & 78 & M & Abdominal cavity & Malignant mesothelioma of hypogastrium & III & $2+$ & 100 \\
\hline 35 & 33 & M & Abdominal cavity & Malignant mesothelioma of retroperitoneum & III & 0 & - \\
\hline 36 & 5 & $\mathrm{~F}$ & Abdominal cavity & Malignant mesothelioma of abdominal cavity & III & $1+$ & 100 \\
\hline 37 & 40 & $\mathrm{~F}$ & Heart & Malignant mesothelioma of left cardiac atrium & $\|$ & 0 & - \\
\hline 38 & 50 & $\mathrm{~F}$ & Heart & Malignant mesothelioma of left cardiac atrium & $\|$ & $2+$ & 100 \\
\hline 39 & 43 & $\mathrm{~F}$ & Heart & Malignant mesothelioma of pericardium & $\|$ & $2+$ & 100 \\
\hline
\end{tabular}


Table 1 continued

\begin{tabular}{|c|c|c|c|c|c|c|c|}
\hline Case nos. & Age & Sex & Organ (anatomic site) & Pathology diagnosis & Stage & CD24 intensity & Proportion (\%) \\
\hline 40 & 43 & $\mathrm{~F}$ & Heart & Malignant mesothelioma of pericardium & । & $2+$ & 100 \\
\hline 41 & 50 & $\mathrm{~F}$ & Heart & Malignant mesothelioma of pericardium & । & $2+$ & 100 \\
\hline 42 & 44 & $\mathrm{~F}$ & Colon & Malignant mesothelioma of tunica serosa coli & $\|$ & 0 & - \\
\hline 43 & 56 & $\mathrm{~F}$ & Colon & Malignant mesothelioma of tunica serosa coli & $\|$ & $2+$ & 100 \\
\hline 44 & 60 & M & Epoploon & Malignant mesothelioma of epoploon & $\|$ & $3+$ & 100 \\
\hline 45 & 60 & M & Epoploon & Malignant mesothelioma of epoploon & $\|$ & $3+$ & 100 \\
\hline 46 & 67 & M & Thoracic cavity & Parietal pleura & & Normal & - \\
\hline 47 & 87 & $\mathrm{~F}$ & Thoracic cavity & Parietal pleura & & Normal & - \\
\hline 48 & 60 & M & Thoracic cavity & Parietal pleura & & Normal & - \\
\hline
\end{tabular}

Each intensity of the positive signal for CD24 was evaluated by two investigators.

The NF2/pcDNA3.1 vector was transfected into NF2KO clones, the p16/pcDNA3.1 vector was transfected into p16-KO clones, and the NF2/pcDNA3.1 and p16/ pcDNA3.1 vectors were transfected into DKO clones using the 4D-Nucleofector System. After transfection, cells were incubated for $48 \mathrm{~h}$, washed with phosphatebuffered saline (PBS), and lysed in loading buffer. The lysates were used for Western blot analysis.

\section{Quantitative real-time PCR}

qRT-PCR analysis for PTN, CD24, BMP7, and CADM1 was performed using SYBR Green I as previously described $^{48}$. Glyceraldehyde 3-phosphate dehydrogenase was used as an internal control. The sequences of the primers for PTN, CD24, BMP7, and CADM1 used in this study are summarized in Supplementary Table S1.

\section{cDNA microarray analysis}

cDNA microarray analysis was performed according to the manufacturer's instructions (Agilent Technologies). In brief, cDNA synthesis and cRNA labeling with cyanine 3 (Cy3) dye were performed using the Agilent Low Input Quick Amp Labeling Kit (Agilent Technologies). Cy3-labeled cRNA was purified, fragmented, and hybridized on a Human Gene Expression $4 \times 44 \mathrm{~K}$ v2 Microarray Chip containing 27,958 Entrez Gene RNAs using a Gene Expression Hybridization kit (Agilent Technologies). Raw and normalized microarray data were submitted to the Gene Expression Omnibus database at the National Center for Biotechnology Information (accession number GSE116000; https://www.ncbi.nlm.nih.gov/geo/ query/acc.cgi?acc $=$ GSE116000). Gene set enrichment analysis was performed according to the instructions.

\section{Cell growth assay}

Cell growth rate was determined using MTT assay. Briefly, cells $\left(1 \times 10^{3}\right.$ per well $)$ were seeded into 96-well plates and cultured for the indicated times. Subsequently,
$10 \mu \mathrm{L}$ of MTT solution ( $5 \mathrm{mg} / \mathrm{mL}$; Sigma-Aldrich) was added to each well and cells were further incubated for $4 \mathrm{~h}$. Next, cell lysis buffer was added to the wells to dissolve the colored formazan crystals produced by MTT. The relative optical density (OD) at $595 \mathrm{~nm}$ was calculated by dividing the OD on day 0 at each time point (days $0,1,3,5$, and 7). The absorbance was measured at $595 \mathrm{~nm}$ using a SpectraMAX M5 spectrophotometer (Molecular Devices, Sunnyvale, CA, USA).

\section{Soft agar colony formation assay}

Soft agar colony formation assay was performed as described previously ${ }^{49}$. Then, cells (200 per well) were seeded in 6-well plates. After 14 days, the cells were stained with MTT and imaged. The number of colonies was counted using Colony Counter software (Keyence, Tokyo, Japan). Data are presented as mean \pm SEM $(n=3)$.

\section{Migration assay}

Cells $\left(2.5 \times 10^{5}\right.$ per well $)$ were seeded in Boyden chambers in 24-well plates $(8 \mu \mathrm{m}$ for 24 -well plates; Millipore, Tokyo, Japan) and the culture medium was added into the lower chambers. After $24 \mathrm{~h}$, cells were stained with crystal violet and imaged. The number of colonies was counted manually under a microscope.

\section{Western blot analysis}

Western blot analysis was performed as described previously ${ }^{49}$. The antibodies used are listed in Supplementary Table S2. Immune complexes were detected using Immuno Star LD (Wako Pure Chemical Industries, Ltd, Osaka, Japan) in conjunction with a LAS-4000 image analyzer (GE Healthcare, Tokyo, Japan).

\section{Immunohistochemistry}

IHC analysis was performed as previously described ${ }^{50}$. Human malignant mesothelioma tissue arrays were 

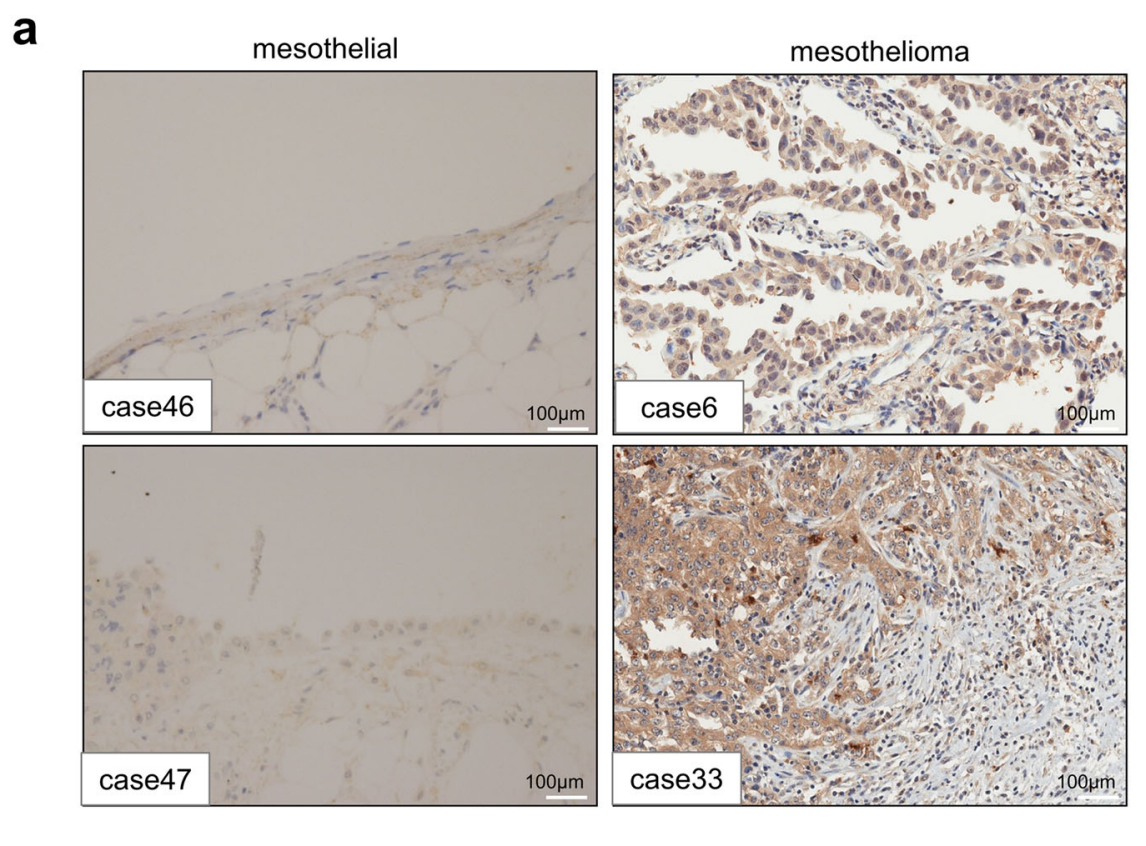

b

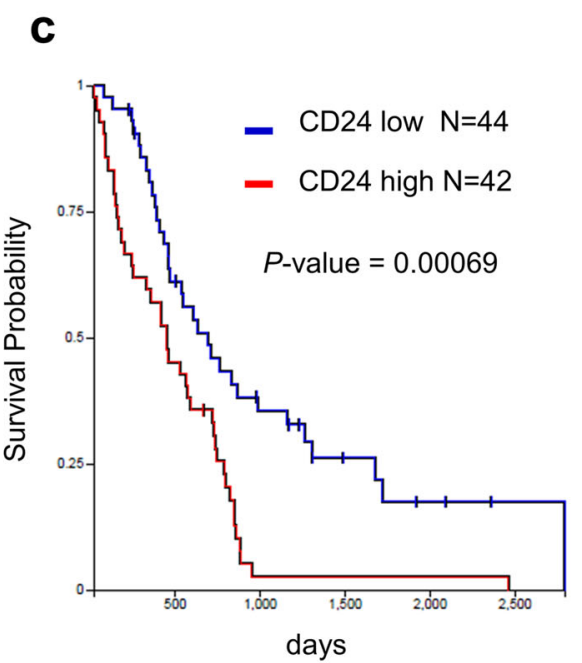

Fig. 6 Immunohistochemical (IHC) analysis of CD24 expression. a Representative IHC results showing CD24 expression in two MPM tissues (right panels, cases 6 and 33) and two normal mesothelium tissues (left panels, cases 46 and 47). b Summary of IHC results in MPM tissues. Immunoreactivity was independently evaluated by two investigators (S.K. and H.M.). Staining intensity was scored as strong $(3+)$, moderate $(2+)$, weak $(1+)$, or negative $(0)$. The number of cases and their staining intensities are shown in the right panel. $\mathbf{c}$ Kaplan-Meier analysis was conducted to assess the value of CD24 in overall survival of MPM patients in TCGA mesothelioma obtained from the UCSC Xena database. Fluorescence values above the median were considered high CD24 expression, whereas fluorescence values below the median were considered low CD24 expression. Scale bar $=100 \mu \mathrm{m}$.

purchased (MS-1001a; Biomax, Houston, TX, USA). Sections were reacted with a primary antibody (CD24 antibody, $2 \mu \mathrm{g} / \mathrm{mL}$; NF2 antibody, $2 \mu \mathrm{g} / \mathrm{mL} ; \mathrm{p} 16$ antibody, $2 \mu \mathrm{g} / \mathrm{mL}$; CADM1 antibody, $2 \mu \mathrm{g} / \mathrm{mL}$, Ki-67 antibody, $2 \mu \mathrm{g} / \mathrm{mL}$ and hematoxylin and eosin). Normal rabbit immunoglobulin $\mathrm{G}$ and omission of primary antibodies were used as negative controls. Immunoreactivity was independently evaluated by two investigators (S.K. and H. M.). The intensity of staining was scored as strong (3+), moderate $(2+)$, weak $(1+)$, or negative $(0)$.

\section{Immunofluorescence}

MeT-5A, HOMC-B1, DKO-MeT-5A, DKO-HOMC-B1, and Y-MESO-9 cells were cultured on glass coverslips and 
fixed using $4 \%$ paraformaldehyde solution for $20 \mathrm{~min}$ at room temperature. Cells were permeabilized with PBS containing $0.1 \%$ Triton $\mathrm{X}-100$ and blocked using PBS containing $7 \%$ serum for $30 \mathrm{~min}$. Then, cells were incubated with $\gamma$-catenin (desmoplakin; BD Transduction Laboratories, San Jose, CA, USA; 1:100 dilution) for $2 \mathrm{~h}$ at room temperature followed by fluorescence staining with anti-mouse IgG Alexa Fluor ${ }^{\circledR}$ 594 (Abcam, Cambridge, UK; 1:200 dilution) and Hoechst (Dojindo, Kumamoto, Japan; 1:200 dilution) for $1 \mathrm{~h}$ at room temperature. Images were acquired using BZ-II (Keyence) with a fluorescence microscope (BZ-X9000; Keyence).

\section{Statistical analysis}

The statistical significance between groups was determined using one-way analysis of variance and Dunnett's comparison. Statistical analyses were performed using SPSS 23.0 program (SPSS, Inc., Chicago, Illinois, USA). Results are expressed as mean \pm SEM.

\section{Acknowledgements}

We thank Dr. Y. Sekido, Division of Molecular Oncology, Aichi Cancer Center Research Institute, for providing normal mesothelial cell line (MeT-5A). This work was partly supported by Hirose International Scholarship foundation research grant and Grants-in-Aid for Scientific Research (KAKENHI) from the Japan Society for the Promotion of Science [19K09292 and 19K08668].

\section{Author details}

'Department of Biochemistry, Aichi Medical University School of Medicine, Nagakute, Aichi, Japan. ${ }^{2}$ Department of Pathology, Aichi Medical University School of Medicine, Nagakute, Aichi, Japan. ${ }^{3}$ Division of Hematology, Department of Internal Medicine, Aichi Medical University School of Medicine, Nagakute, Aichi, Japan

\section{Conflict of interest}

The authors declare that they have no conflict of interest.

\section{Publisher's note}

Springer Nature remains neutral with regard to jurisdictional claims in published maps and institutional affiliations.

The online version of this article (https://doi.org/10.1038/s41420-020-00364-1) contains Supplementary Material, which is available to authorized users.

Received: 11 June 2020 Revised: 28 September 2020 Accepted: 30 October 2020

Published online: 18 November 2020

\section{References}

1. Carbone, C. et al. Mesothelioma: scientific clues for prevention, diagnosis, and therapy. CA Cancer J. Clin. 69, 402-429 (2019).

2. Patel, S. C. \& Dowell, J. E. Modern management of malignant pleural mesothelioma. Lung Cancer 7, 63-72 (2016).

3. Vogelzang, N. J. et al. Phase III study of pemetrexed in combination with cisplatin versus cisplatin alone in patients with malignant pleural mesothelioma. J. Clin. Oncol. 21, 2636-2644 (2003).

4. Carbone, M. et al. Consensus report of the 2015 Weinman International Conference on Mesothelioma. J. Thorac. Oncol. 11, 1246-1262 (2016).

5. Carbone, M. \& Bedrossian, C. W. The pathogenesis of mesothelioma. Semin. Diagn. Pathol. 23, 56-60 (2006).

6. Fung, H., Kow, Y. W., Van, H. B. \& Mossman, B. T. Patterns of 8 hydroxydeoxyguanosine formation in DNA and indications of oxidative stress in rat and human pleural mesothelial cells after exposure to crocidolite asbestos. Carcinogenesis 18, 825-832 (1997).

7. Sekido, Y. Molecular pathogenesis of malignant mesothelioma. Carcinogenesis 34, 1413-1419 (2013).

8. Testa, J. R. et al. Germline BAP1 mutations predispose to malignant mesothelioma. Nat. Genet. 43, 1022-1025 (2011).

9. Bott, M. et al. The nuclear deubiquitinase BAP1 is commonly inactivated by somatic mutations and 3p21.1 loss in malignant pleural mesothelioma. Nat. Genet. 43, 668-672 (2011).

10. Guo, G. et al. Whole-exome sequencing reveals frequent genetic alterations in BAP1, NF2, CDKN2A, and CUL1 in malignant pleural mesothelioma. Cancer Res. 75, 264-269 (2015).

11. Cheng, J. Q. et al. p16 alterations and deletion mapping of 9p21-p22 in malignant mesothelioma. Cancer Res. 54, 5547-5551 (1994).

12. Thurneysen, C. et al. Functional inactivation of NF2/merlin in human mesothelioma. Lung Cancer 64, 140-147 (2009).

13. Bianchi, A. B. et al. High frequency of inactivating mutations in the neurofibromatosis type 2 gene (NF2) in primary malignant mesotheliomas. Proc. Natl Acad. Sci. USA 92, 10854-10858 (1995).

14. Sheffield, B. S. et al. BAP1 immunohistochemistry and p16 FISH to separate benign from malignant mesothelial proliferations. Am. J. Surg. Pathol. 39 977-982 (2015).

15. Farzin, M. et al. Loss of expression of BAP1 predicts longer survival in mesothelioma. Pathology 47, 302-307 (2015).

16. Nasu, M. et al. High incidence of somatic BAP1 alterations in sporadic malignant mesothelioma. J. Thorac. Oncol. 10, 565-576 (2015).

17. Yoshikawa, Y. et al. High-density array-CGH with targeted NGS unmask multiple noncontiguous minute deletions on chromosome 3p21 in mesothelioma. Proc. Natl Acad. Sci. USA 113, 13432-13437 (2016).

18. Wahiduzzaman, M. et al. Establishment and characterization of CRISPR/Cas9mediated NF2(-/) human mesothelial cell line: molecular insight intofibroblast growth factor receptor 2 in malignant pleural mesothelioma. Cancer Sci. 110, 180-193 (2019)

19. Kukuyan, A. M. et al. Inactivation of Bap1 cooperates with losses of Nf2 and Cdkn2a to drive the development of pleural malignant mesothelioma in conditional mouse models. Cancer Res. 79, 4113-4123 (2019).

20. Schabath, H., Runz, S., Joumaa, S. \& Altevogt, P. CD24 affects CXCR4 function in pre-B lymphocytes and breast carcinoma cells. J. Cell. Sci. 119, 314-325 (2006).

21. Kristiansen, G. et al. CD24 is expressed in ovarian cancer and is a new independent prognostic marker of patient survival. Am. J. Pathol. 161, 1215-1221 (2002).

22. Kristiansen, G. et al. CD24 is an independent prognostic marker of survival in non-small cell lung cancer patients. Br. J. Cancer 88, 231-236 (2003).

23. Ayre, D. C. et al. CD24 induces changes to the surface receptors of B cell microvesicles with variable effects on their RNA and protein cargo. Sci. Rep. 7, 8642 (2017).

24. Deng, J. et al. CD24 expression as a marker for predicting clinical outcome in human gliomas. J. Biomed. Biotechnol. 2012, 517172 (2012).

25. Kristiansen, $\mathrm{G}$. et al. CD24 expression is a new prognostic marker in breast cancer. Clin. Cancer Res. 9, 4906-4913 (2003).

26. Sano, A. et al. CD24 expression is a novel prognostic factor in esophageal squamous cell carcinoma. Ann. Surg. Oncol. 16, 506-514 (2009).

27. Jacob, J. et al. Expression of CD24 in adenocarcinomas of the pancreas correlates with higher tumor grades. Pancreatology 4, 454-460 (2004).

28. $\mathrm{Su}, \mathrm{M}$. C., Hsu, C., Kao, H. L. \& Jeng, Y. M. CD24 expression is a prognostic factor in intrahepatic cholangiocarcinoma. Cancer Lett. 235, 34-39 (2006).

29. Lu, S. et al. CD24 regulates sorafenib resistance via activating autophagy in hepatocellular carcinoma. Cell Death Dis. 9, 646 (2018).

30. Tanaka, T. et al. CD24 expression as a marker for predicting clinical outcome and invasive activity in uterine cervical cancer. Oncol. Rep. 34, 2282-2288 (2015).

31. Nakamura, K. et al. CD24 expression is a marker for predicting clinical outcome and regulates the epithelial-mesenchymal transition in ovarian cancer via both the Akt and ERK pathways. Oncol. Rep. 37, 3189-3200 (2017).

32. Lubeseder-Martellato, C. et al. Membranous CD24 drives the epithelial phenotype of pancreatic cancer. Oncotarget 7, 49156-49168 (2016).

33. Salnikov, A. V. et al. Antibody targeting of CD24 efficiently retards growth and influences cytokine milieu in experimental carcinomas. Br. J. Cancer 108, 1449-1459 (2013).

34. Barkal, A. A. et al. CD24 signalling through macrophage Siglec-10 is a target for cancer immunotherapy. Nature 572, 392-396 (2019). 
35. Chan, S. H. et al. Identification of the novel role of CD24 as an oncogenesis regulator and therapeutic target for triple-negative breast cancer. Mol. Cancer Ther. 18, 147-161 (2019).

36. Eyvazi, S., Kazemi, B., Dastmalchi, S. \& Bandehpour, M. Involvement of CD24 in multiple cancer related pathways makes it an interesting new target for cancer therapy. Curr. Cancer Drug Targets 18, 328-336 (2018).

37. Kowalczyk, A. P. \& Green, K. J. Structure, function, and regulation of desmosomes. Prog. Mol. Biol. Transl. Sci. 116, 95-118 (2013).

38. Arik, D., Can, C., Dündar, E., Kabukçuoğlu, S. \& Paşaoğlu, Ö. Prognostic significance of CD24 in clear cell renal cell carcinoma. Pathol. Oncol. Res. 23 409-416 (2017)

39. Yamazaki, H. et al. Characterization of cancer stem cell properties of CD24 and CD26-positive human malignant mesothelioma cells. Biochem. Biophys. Res. Commun. 419, 529-536 (2012)

40. Maloney, D. G. et al. IDEC-C2B8 (Rituximab) anti-CD20 monoclonal antibody therapy in patients with relapsed low-grade non-Hodgkin's lymphoma. Blood 90, 2188-2195 (1997).

41. Leget, G. A. \& Czuczman, M. S. Use of rituximab, the new FDA-approved antibody. Curr. Opin. Oncol. 10, 548-551 (1998).

42. Aruga, N. et al. Epithelial-mesenchymal transition (EMT) is correlated with patient's prognosis of lung squamous cell carcinoma. Tokai J. Exp. Clin. Med. 43, 5-13 (2018).
43. Hutz, K., Zeiler, J., Sachs, L., Ormanns, S. \& Spindler, V. Loss of desmoglein 2 promotes tumorigenic behavior in pancreatic cancer cells. Mol. Carcinog. $\mathbf{5 6}$ 1884-1895 (2017).

44. Shiina, $\mathrm{H}$. et al. Functional loss of the $\gamma$-catenin gene through epigenetic and genetic pathways in human prostate cancer. Cancer Res. 65, 2130-2138 (2005)

45. Dubash, A. D. \& Green, K. J. Desmosomes. Curr. Biol. 21, R529-R531 (2011).

46. Kakiuchi, T. et al. Modeling mesothelioma utilizing human mesothelial cells reveals involvement of phospholipase-C beta 4 in YAP-active mesothelioma cell proliferation. Carcinogenesis 37, 1098-1109 (2016).

47. Ran, F. A. et al. Genome engineering using the CRISPR-Cas9 system. Nat. Protoc. 8, 2281-2308 (2013).

48. Yamaji, M. et al. Novel ATP-competitive Akt inhibitor afuresertib suppresses the proliferation of malignant pleural mesothelioma cells. Cancer Med. $\mathbf{6}$, 2646-2659 (2017)

49. Wahiduzzaman, M. et al. Novel combined Ato-C treatment synergistically suppresses proliferation of bcr-abl-positive leukemic cells in vitro and in vivo. Cancer Lett. 433, 117-130 (2018).

50. Ito, T. et al. Loss of YAP1 defines neuroendocrine differentiation of lung tumors. Cancer Sci. 107, 1527-1538 (2016). 